\title{
Frontières
}

\section{Un événement culturel sur le thème « Peut-on célébrer la mort?»}

Volume 18, numéro 1, automne 2005

Hélas, célébrer la mort!

URI : https://id.erudit.org/iderudit/1074320ar

DOI : https://doi.org/10.7202/1074320ar

Aller au sommaire du numéro

Éditeur(s)

Université du Québec à Montréal

ISSN

1180-3479 (imprimé)

1916-0976 (numérique)

Découvrir la revue

Citer ce document

(2005). Un événement culturel sur le thème " Peut-on célébrer la mort ? ". Frontières, 18(1), 68-69. https://doi.org/10.7202/1074320ar d'utilisation que vous pouvez consulter en ligne.

https://apropos.erudit.org/fr/usagers/politique-dutilisation/ 


\section{Un événement culturel sur le thème}

\section{«PEUT-ON CÉLÉBRER LA MORT?»}

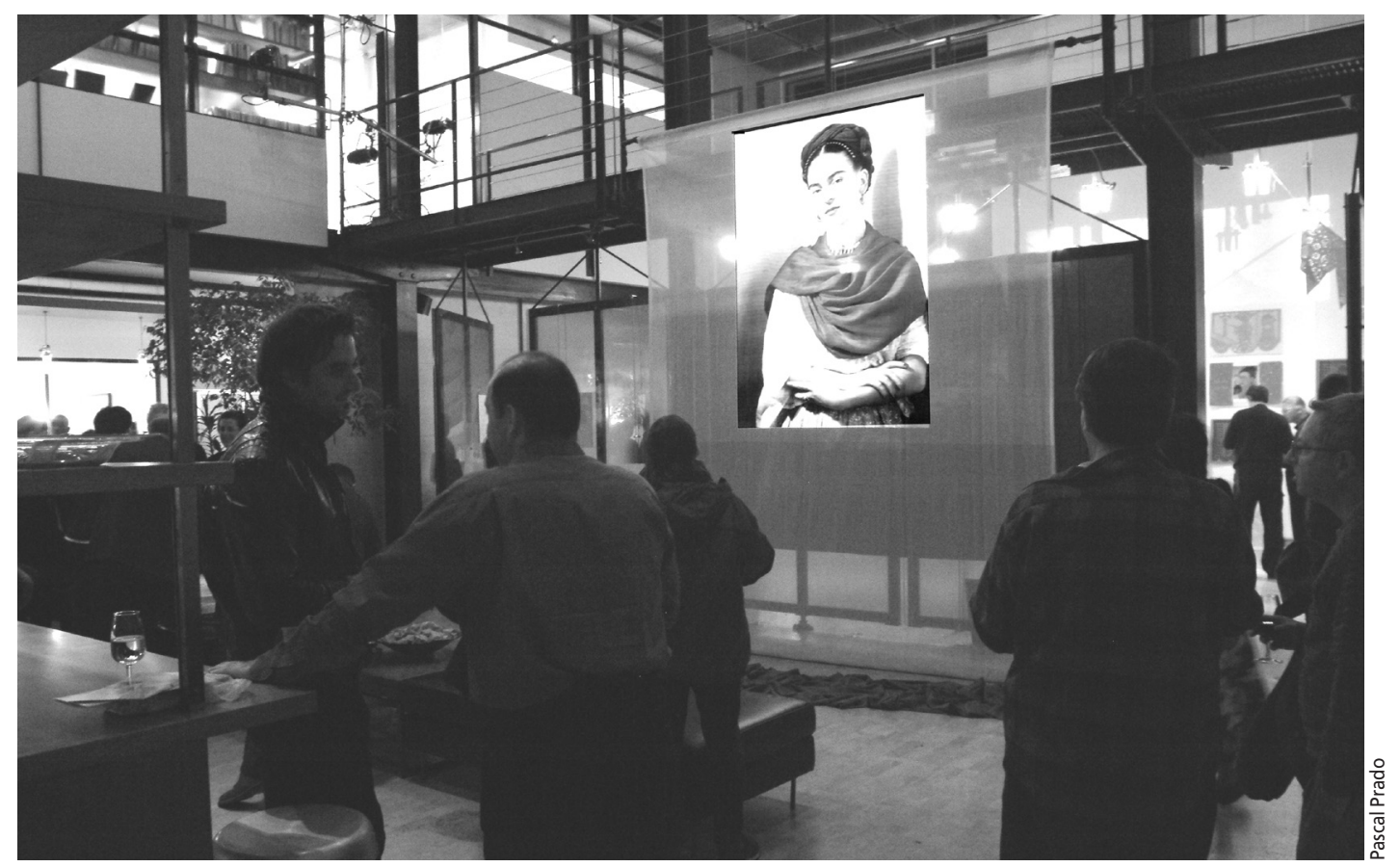

Du 4 au 7 novembre 2004, Montréal accueillait «La fête des Morts mexicaine: un espace de célébration». Cet événement

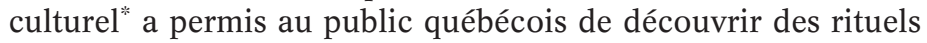
différents, parfois festifs, très éloignés de notre conception moderne de la mort. L'événement s'est tenu à l'Espace Memoria, un complexe funéraire qui se distingue par son aménagement architectural polyvalent et qui est doté d'un bibliocafé, le salon b, un lieu convivial qui peut accueillir conférences et tables rondes et où l'on peut consulter des centaines d'ouvrages relatifs au deuil. «Nous ne voulons pas nous limiter à organiser des funérailles, explique Jocelyne Dallaire Légaré, présidente de la maison funéraire. Parce que nous sentons que les gens cherchent des voies nouvelles, des façons autres d'approcher la mort, nous faisons de nos lieux des espaces de réflexion ouverts à toutes formes d'initiatives.».
Les organisateurs de l'événement ont relevé le défi d'attirer une foule nombreuse. Les caractéristiques inspirantes du lieu et le programme varié des activités offertes ont permis à l'auditoire de pénétrer dans un espace de célébration inédit.

En permanence durant les célébrations, on pouvait voir un autel des morts mexicain à la mémoire de Frida Kahlo, par l'artiste Arturo Jacal; La caresse de l'adieu, une exposition de photos inédites et troublantes de Dominique Malaterre; et Passage, une projection de collages virtuels signés Marie Cornellier. On pouvait également assister à l'intervention théâtrale Noces de mort: L'impératrice Charlotte du Mexique de Lori Hazine Poisson, à une table ronde autour du thème «Peut-on célébrer la mort? » et à une conférence de Daniel Castillo avec images et musique d'époque sur «La fête des Morts comme espace de célébration au Mexique». Ces différents volets exprimaient et interrogeaient la mort conçue comme lieu de dialogue, comme pont entre deux mondes.

\footnotetext{
* Note de la rédaction: Le thème de ce numéro de Frontières s'est construit dans le sillage de cet événement, élargissant à d'autres interlocuteurs la réflexion amorcée lors de la table ronde tenue autour de la question «Peut-on célébrer la mort?». Frontières remercie Alfred Dallaire MEMORIA qui a fourni des extraits de son communiqué de presse pour contribuer à présenter tous les acteurs qui ont fait le succès de cet événement et que nous tenions à nommer. Leur contribution ne prend pas nécessairement la forme d'un article mais leur présence a été une source d'inspiration et nous tenons à leur rendre hommage.
} 
L'intervention théâtrale

Noces de mort: L'impératrice Charlotte du Mexique de Lori Hazine Poisson.

Sur la page de gauche, l'écran utilisé pour la projection Passage

de Marie Cornellier.
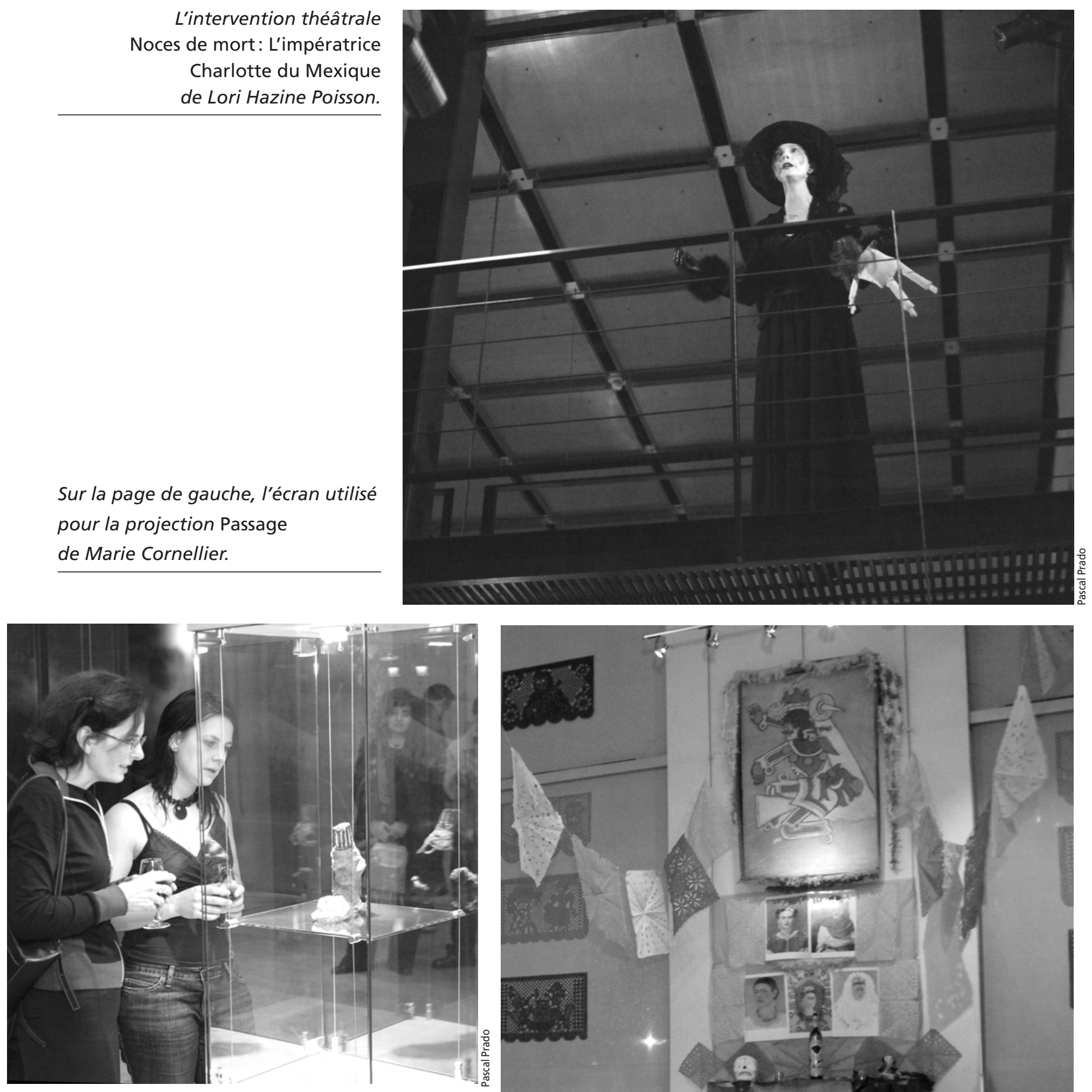

Jeunes devant une des vitrines de l'exposition d'art mexicain.

Autel des morts mexicain par l'artiste Arturo Jacal.

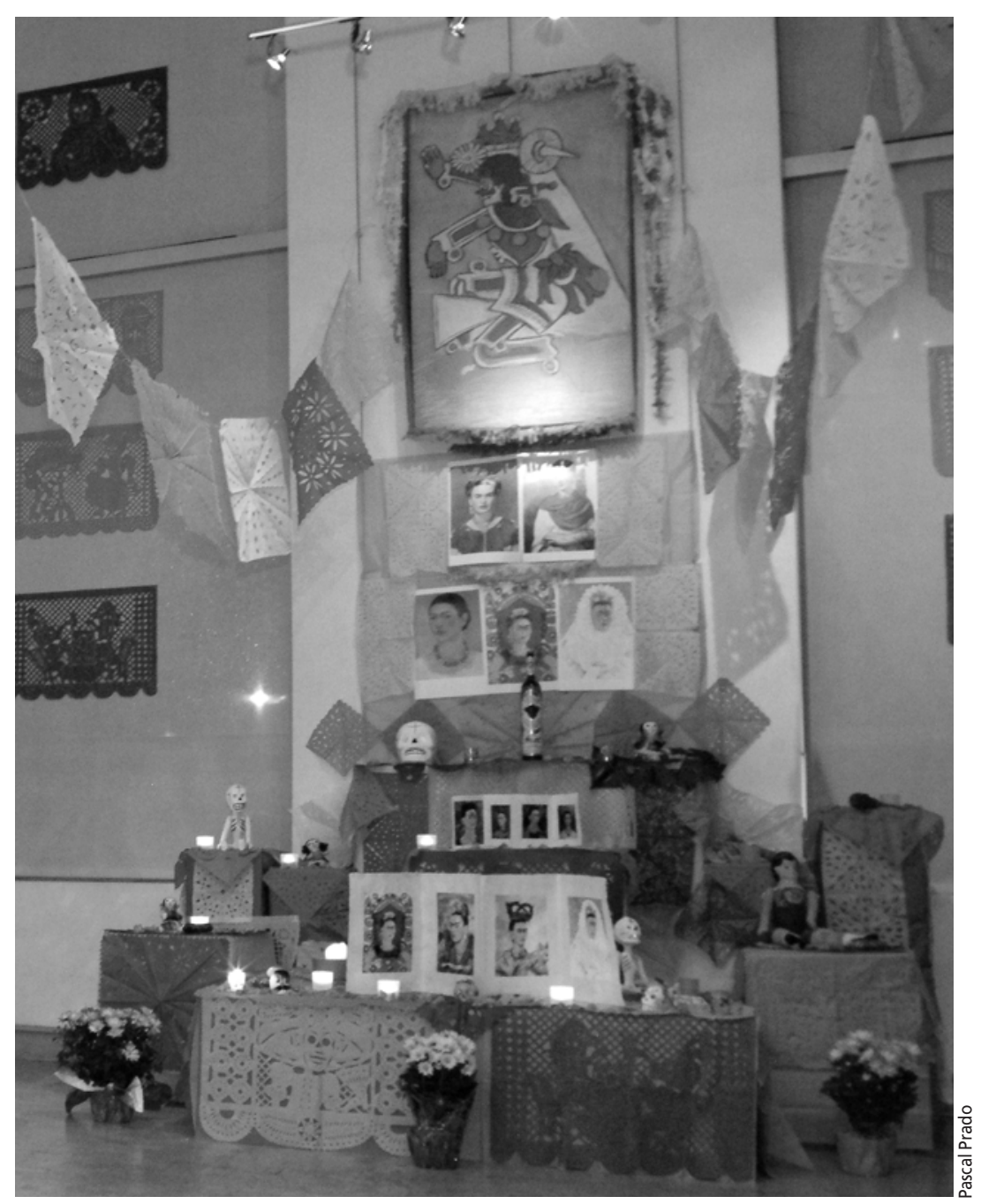

